\title{
Synthesis and characterization of soluble ester-containing polyimide alignment layers with high voltage holding ratio features and potential applications in TFT-LCDs
}

\author{
X.X.Zhi ${ }^{1}$, H. S. Bi ${ }^{1}$, J. G. Liu ${ }^{1}$, Y. S. Gao ${ }^{1}$, Y. L. Zhang ${ }^{1}$, Y. C. Zhou ${ }^{1}$, Y. Zhang ${ }^{1}, X . W u^{1}$, \\ X. M. Zhang $^{2}$ \\ ${ }^{1}$ Beijing Key Laboratory of Materials Utilization of Nonmetallic Minerals and Solid Wastes, National Laboratory of \\ Mineral Materials, School of Materials Science and Technology, China University of Geosciences, 100083 Beijing, China \\ ${ }^{2}$ School of Electrical Engineering, Beijing Jiaotong University, 100044 Beijing, China
}

Received 8 April 2019; accepted in revised form 29 May 2019

\begin{abstract}
Novel ester-containing polyimide (PI) resins have been synthesized from an alicyclic dianhydride monomer, 4,4'dihydroxybiphenyldicyclohexanecarboxylate-3,3',4,4'-tetracarboxylic acid dianhydride (HTABP) and various aromatic diamines. The derived PI resins (PI-1 PI-5) were easily soluble in $N$-methyl-2-pyrrolidinone (NMP) and gamma-butyrolactone (GBL). The PI alignment agents prepared from the HTABP-PI resins, NMP solvent, and the butyl cellulose (BC) leveling agent with a solid content of $6 \mathrm{wt} \%$ showed good stability during the storage at $25^{\circ} \mathrm{C}$ for half a year. Smooth and uniform PI alignment layers were formed by spin-coating the PI varnishes onto indium tin oxide (ITO) substrates, followed by thermally baking at the temperature up to $230^{\circ} \mathrm{C}$. Liquid crystal (LC) cells were successfully fabricated by using the rubbing treated PI layers as the alignment components for LC molecules. The LC cells fabricated with the newly-developed PI alignment layers exhibited good electro-optical properties with the pretilt angles around $1.26-2.82^{\circ}$ and voltage holding ratio $(V H R)$ as high as $98.36 \%$ at room temperature. The residual direct current voltage $(R D C)$ values of the HTABP-PI alignment layers were in the range of $915-2146 \mathrm{mV}$ due to the high volume resistivity values of the PI layers. In addition, the HTABPPI layers showed good thermal stability with the $5 \%$ weight loss temperatures $\left(T_{5 \%}\right)$ higher than $415^{\circ} \mathrm{C}$ and glass transition temperatures $\left(T_{\mathrm{g}}\right)$ in the range of $150.5-201.4^{\circ} \mathrm{C}$.
\end{abstract}

Keywords: industry applications, polyimide, alignment layer, TFT-LCD, voltage holding ratio

\section{Introduction}

Polyimide (PI) represents a class of high performance heteroaromatic polymers characterized by excellent thermal and environmental stability, high mechanical and dielectric properties as well as flexible molecular structure designability [1-3]. Various functionalities have been achieved for PIs via elaborate combination of specific dianhydride and diamine monomers so as to meet the property demands of high-tech applications [4-6]. Among the various functional PIs, semi-alicyclic PIs derived from alicyclic dianhydrides and aromatic diamines proved to possess the best combined properties considering the polymerization reactivity and the acidity/basicity of the starting monomers [7]. Thus, such kinds of semi-alicyclic PIs usually exhibited superior thermal and mechanical properties, and higher molecular weights to their analogous PIs derived from aromatic dianhydrides and alicyclic diamines or from both of alicyclic dianhydride and diamines [8].

Good comprehensive properties of semi-alicyclic PIs derived from alicyclic dianhydrides and aromatic diamines make them much attractive in optoelectronic fields in recent years [9-11]. The successful 
application of the semi-alicyclic PIs as alignment layers for liquid crystal (LC) molecules in advanced liquid crystal display devices (LCDs) could best reflect the glorious developing future for such polymers [12]. As one of the most important components for LCD devices, alignment layers mainly serve as the components that induce the pre-alignment of randomly-aligned rod LC molecules so as to align uniformly when the voltage was applied [13]. According to the molecular design of polymer alignment layers for advanced LCDs summarized in the literature [13], several property requirements should be addressed, including unidirectional liquid crystal alignment, good thermal stability, printability, low curing temperature, high voltage holding ratio $(V H R)$, and suitable pretilt angles. PIs proved to be one of the best candidates as the alignment layers for various modes of LCDs, including twisted nematic LCD (TN-LCD), super-twisted nematic LCD (STN-LCD), and the full-color thin film transistor driven liquid crystal display devices (TFT-LCD) due to the good comprehensive properties [14]. For the state-of-art TFT-LCDs, PI alignment layers became one of the most important factors affecting the display qualities of the devices [15]. Various electro-optical properties on the display quality of TFT-LCDs, including image sticking, flickering, distortion, contrast and other issues proved to be closely related with the PI alignment layers for LC molecules. For example, in TFTLCDs, voltage holding ratio $(V H R)$ is a critical electro-optical parameter, which is defined as the fraction of voltage remaining over the LC cells after a certain length of open circuit time [16]. It means that $V H R$ values reflect the ability to retain a voltage during the time between pixel updates (frame period) in the LC cells. Higher VHR features can usually provide better contrast and low image flickering for TFTLCDs [17]. Another example is the residual direct current voltage $(R D C)$ feature of the LC cells, which is highly related with the image sticking issue of the LCD devices. The image sticking is the phenomenon in which the previous pattern is visible when the next pattern is addressing, whose generation is mainly attributed to the existence of $R D C$ in the LC cells [18]. It is speculated that $R D C$ originates from ion impurities of organic materials in color filters, alignment layers, LCs, and organic black matrix [19]. Enrichment of impurity ions onto the surface of the PI alignment layers usually occur when the external driving direct current voltage is applied. The accumulated impurity ions still exist at the interface of alignment layers and LC layers even the voltage is removed, leading to the generation of $R D C$. $R D C$ could be minimized by adjusting the absorption/desorption of ions in the organic materials in LCDs [20]. It has been well established that the PI alignment layer influences both of the VHR and RDC parameters of the TFT-LCDs [21]. It has been proven that LC cells fabricated with PI alignment layers with high electrical resistivity can usually lead a high VHR feature for the devices [22]. However, if the electrical resistivity of the PI alignment layer is too high, it is not beneficial for the releasing of the accumulated ionized charge, leading to the increase of the $R D C$ value. That is to say, the choice of PI alignment layers is usually contradictory in improving $V H R$ and reducing $R D C$ of the LC cells. The higher the resistivity of the PI alignment layer, the better the $V H R$ characteristic of the device is; however, the $R D C$ characteristic of the devices deteriorates simultaneously. Therefore, it is a challenging work to achieve both of the high $V H R$ and low $R D C$ features of the TFT-LCD devices via choice of suitable PI alignment layers.

From the viewpoint of chemical structure, PI can mainly exist in two forms, poly(amic acid) (PAA) precursor and the completely or partially imidized PI. As a kind of PI precursor containing polar carboxyl group $(-\mathrm{COOH})$ and amide bond $(-\mathrm{CONH}-)$ in the structure, PAA often has relatively lower resistivity than that of less-polar imidized PI. Therefore, the charge transfer and releasing rate are often different in the molecular structures of PAA and imidized PI. It has been found that the current density of the PI film from PAA was higher than that of the PI film from imidized PI at the same electric field [23]. Meanwhile, the decay rate of the residual electrostatic charges on the PI films becomes faster in the PAA type of film than that in the imidized PI type of PI film by comparing the ion hopping distance and activation energy in the polymers. This discovery provides an efficient pathway achieving both of the high $V H R$ and low $R D C$ features for the LC cells via combining the PAA and imidized PI in the alignment agents. After thermal curing, anisotropic microstructure might form in the derived PI layers from PAA and imidized PI, respectively. Actually, such methodology has been used in the research and development of PI alignment layers for TFT-LCDs, in which hybrids of PAA and imidized PI, or PAAs with different structural characteristics have been performed [24, 25]. 
The derived PI alignment layers usually exhibit good combined electro-optical properties, including high $V H R$, low $R D C$, and good optical transparency.

Most of the PI alignment layers possess the semi-alicyclic structure due to the good comprehensive properties mentioned above. Various PAAs derived from alicyclic dianhydrides, such as 1,2,3,4-cyclobutanetetracarboxylic dianhydride (CBDA) and aromatic diamines have been successfully developed for high performance alignment layers [26, 27]. By contrast, the varieties of imidized PI components for alignment layers development are quite limited due to the very limited commercially available alicyclic dianhydrides. Nishikawa and co-workers reported a series of organo-soluble PI alignment layers prepared from 2,3,5-tricarboxycyclopentyl acetic dianhydride (TCA$\mathrm{AH})$ and aromatic diamines [28-30]. The liquid crystal cells fabricated with the organo-soluble PI alignment layer exhibited low curing temperature $\left(<200^{\circ} \mathrm{C}\right)$, high $V H R$, and good alignment ability to liquid crystal molecules.

In the current work, as one of continuous work developing high performance PI materials for optoelectronic applications [31-34], a series of imidized PIs were prepared from an ester-linked semi-alicyclic dianhydride and aromatic diamines. Compared with the PI alignment layers derived from substitutedtetralin dianhydrides in our previous work [34], the current PI systems are expected to provide better comprehensive properties for the derived PI alignment layers, including higher optical transparency, lower curing temperature, and higher degree of imidization at the TFT-LCD processing temperature $\left(230^{\circ} \mathrm{C}\right)$. The low-conjugated and semi-alicyclic dianhydride moiety might endow the PIs good solubility in organic solvents; thus achieving low curing temperature and high $V H R$ features for the alignment layers. The rigid-rod biphenylene unit and ester linkages in the PIs guarantee the good thermal stability of the PI layers. The essentially non-planar and bent skeleton structure for the ester-linked molecular chains might achieve liquid crystal alignment with suitable pretilt angles. Thus, the current ester-linked semi-alicyclic PIs might be good candidates as alignment layers for TFT-LCDs according to the molecular design in the reference [13]. To the best of our knowledge, there are few works on the ester-linked PI alignment layers for TFT-LCD applications in the literature. The effects of the molecular structure of the PIs on their thermal and optical properties were investigated in detail. At last, the potential applications of the developed semi-alicyclic PI alignment layers in TFT-LCDs were preliminarily evaluated by investigating the $V H R$ and $R D C$ features of the LC cells fabricated with the HTABP-PIs.

\section{Experiments}

\subsection{Materials}

4,4'-Dihydroxybiphenyldicyclohexanecarboxylate3,3',4,4'-tetracarboxylic acid dianhydride (HTABP) was synthesized in our laboratory according to the literature [33]. In a typical embodiment, HTABP was prepared by the esterification reaction of chlorinated cyclohexanetricarboxylic anhydride (HTMA) and 4,4'-bisphenol using $N, N$-dimethylacetamide (DMAc) as the solvent and pyridine as the hydrochloric acid absorber at room temperature for $24 \mathrm{~h}$. It was purified by recrystallization from acetic anhydride and dried in vacuo at $100^{\circ} \mathrm{C}$ for $24 \mathrm{~h}$. Yield: $76.7 \%$. Melting point: $254.4^{\circ} \mathrm{C}$ (DSC peak temperature). The aromatic diamines, including $4,4^{\prime}$-methylenedianiline (MDA), 1,4-bis[2-(4-aminophenyl)-2-propyl]benzene (BisP), and 1,3-bis[2-(4-aminophenyl)-2-propyl]benzene (BisM) were purchased from Tokyo Chemical Industry (Tokyo, Japan) and used as received. 4,4'Diaminodiphenylamine (NDA) and 1,3-bis(4-aminophenoxy)propane (PPDA) were synthesized in our laboratory, respectively according to the literature $[35,36]$. High-purity solvents including $N$-methyl2-pyrrolidinone (NMP), N,N-dimethylacetamide (DMAc), and butyl cellulose (BC) were all purchased from Beijing Yili Fine Chemicals (Beijing, China), and further purified by distillation prior to use. The other commercially available reagents were used without further purification.

\subsection{Measurements}

Inherent viscosity was measured using an Ubbelohde viscometer with a $0.5 \mathrm{~g} \cdot \mathrm{dl}^{-1}$ NMP solution at $25^{\circ} \mathrm{C}$. The number average molecular weight $\left(M_{\mathrm{n}}\right)$ and weight average molecular weight $\left(M_{\mathrm{w}}\right)$ of the PI resins were measured using a gel permeation chromatography (GPC) system (Shimadzu, Kyoto, Japan) with the HPLC grade NMP as the mobile phase at a flow rate of $1.0 \mathrm{ml} / \mathrm{min}$. Polystyrene (Shodex, Type: SM-105, Showa Denko Co. Ltd., Japan) was used as the standards. Attenuated total reflectance Fourier transform infrared (ATR-FTIR) spectrum was obtained on a Bruker Tensor-27 FT-IR spectrometer (Ettlingen, Germany). Nuclear magnetic resonances 
( ${ }^{1} \mathrm{H}-\mathrm{NMR}$ and ${ }^{13} \mathrm{C}-\mathrm{NMR}$ ) were performed on an AV 400 spectrometer (Ettlingen, Germany) operating at $400 \mathrm{MHz}$ in DMSO- $d_{6}$. Field emission scanning electron microscopy (FE-SEM) was carried out using a Technex Lab Tiny-SEM 1540 (Tokyo, Japan) with an accelerating voltage of $15 \mathrm{kV}$ for imaging. $\mathrm{Pt} / \mathrm{Pd}$ was spattered on each film in advance of the measurements. Ultraviolet-visible (UV-Vis) spectra were recorded on a Hitachi U-3210 spectrophotometer (Tokyo, Japan) at room temperature.

The degree of imidization (DI) of the PI layers at $230^{\circ} \mathrm{C}$ was determined by the ATR-FTIR measurements and calculated according to equation of $D I=\left(A_{1381} / \mathrm{A}_{1512}\right)_{230} /\left(A_{1381} / A_{1512}\right)_{300}$, where $A_{1381}$ and $A_{1512}$ stand for the absorption intensity of the $\mathrm{C}-\mathrm{N}$ stretching vibration in imide rings and stretching vibration of $\mathrm{C}=\mathrm{C}$ in phenyl rings, respectively [37]. The absorption of $\mathrm{C}=\mathrm{C}$ bonds is used as an internal standard peak, whose intensity will not change with the imidization temperature. The absorption of imide carbonyl is used as the indicator peak, whose intensity will change with the imidization temperature. The footnotes of ' 230 ' and ' 300 ' indicate the imidization temperature.

Differential scanning calorimetry (DSC) and thermogravimetric analysis (TGA) were recorded on a TA-Q100 and TA-Q50 thermal analysis system (Delaware, USA) at a heating rate of $10^{\circ} \mathrm{C} / \mathrm{min}$ in nitrogen, respectively. The glass transition temperatures $\left(T_{\mathrm{g}} \mathrm{s}\right)$ of the PIs were recorded as the second heating run from 50 to $300^{\circ} \mathrm{C}$. The volume resistivity of HTABP-PI films were measured at room temperature according to ASTM D-257-14 using a PC68 digital high-voltage and high-resistance megger instrument (Shanghai, China). The samples were dried at $100^{\circ} \mathrm{C}$ for $1 \mathrm{~h}$ prior to measurement.

Solubility was investigated by mixing $1.0 \mathrm{~g}$ of the PI resin and $9.0 \mathrm{~g}$ of the solvent tested $(10 \mathrm{wt} \%$ solid content), and then stirred for $24 \mathrm{~h}$ at room temperature. The solubility was determined visually as three grades: completely soluble $(++)$, partially soluble $(+-)$, and insoluble (-), wherein complete soluble indicates a homogenous and clean state without phase separation, precipitation or gel formation, and insoluble indicates no change of the resin in the appearance.

\subsection{Synthesis}

\subsubsection{Polyimides synthesis}

The polymers were synthesized from HTABP and aromatic diamines via a two-step chemical imidization procedure. As an illustration, PI-3 was prepared with a procedure as follows. A $250 \mathrm{ml}$ three-necked, round-bottomed flask equipped with a mechanical stirrer, a Dean-Stark trap and a nitrogen inlet was charged with PPDA (5.1664 g, $20 \mathrm{mmol})$ and newly distilled NMP $(38.3 \mathrm{~g})$ at room temperature $\left(25^{\circ} \mathrm{C}\right)$. Then, to the clear diamine solution, HTABP (10.9304 g, $20 \mathrm{mmol}$ ) was added in one batch and an additional volume of NMP $(10.0 \mathrm{~g})$ was added to wash the residual dianhydride, and at the same time to adjust the solid content of the reaction system to be $25 \mathrm{wt} \%$. After stirring in nitrogen for $24 \mathrm{~h}$, a mixture of acetic anhydride $(10.21 \mathrm{~g}, 100 \mathrm{mmol})$ and pyridine $(6.33 \mathrm{~g}, 80 \mathrm{mmol})$ was added. The reaction mixture was stirred at $25^{\circ} \mathrm{C}$ for $24 \mathrm{~h}$. The obtained colorless and viscous solution was slowly dripped into an excess of ethanol. The precipitated fibrous PI-3 resin was obtained and first dried in fume hood at room temperature overnight. Then, the PI-3 resin was further dried at $80^{\circ} \mathrm{C}$ under vacuum for $24 \mathrm{~h}$. PI-3 was obtained as a white fibrous resin. Yield: $14.76 \mathrm{~g}(96 \%)$.

PI-3 (HTABP-PPDA). ${ }^{1} \mathrm{H}-\mathrm{NMR}$ (DMSO- $\left.d_{6}, \mathrm{ppm}\right)$ : 7.70-7.68 $(d, 4 \mathrm{H}), 7.22-7.18(\mathrm{~m}, 8 \mathrm{H}), 7.05-7.03(d$, $4 \mathrm{H}), 4.18-4.15(m, 4 \mathrm{H}), 3.24-3.21(m, 2 \mathrm{H}), 3.19-$ $3.12(m, 2 \mathrm{H}), 2.90-2.76(m, 2 \mathrm{H}), 2.44-2.31(m, 2 \mathrm{H})$, 2.26-2.06 ( $m, 6 \mathrm{H}), 2.05-1.92(\mathrm{~m}, 2 \mathrm{H}), 1.87-1.73(\mathrm{~m}$, $2 \mathrm{H})$, and $1.62-1.43(\mathrm{~m}, 2 \mathrm{H})$.

The other PI resins were prepared according to a similar procedure like PI-3 except that PPDA was changed to MDA for PI-1, NDA for PI-2, BisP for PI-4, and BisM for PI-5.

PI-1 (HTABP-MDA). ${ }^{1}$ H-NMR (DMSO- $\left.d_{6}, \mathrm{ppm}\right)$ : 7.70-7.68 $(d, 4 \mathrm{H}), 7.36-7.34(d, 4 \mathrm{H}), 7.22-7.20(\mathrm{~m}$, $8 \mathrm{H}), 4.02(\mathrm{~s}, 2 \mathrm{H}), 3.30-3.26(\mathrm{~m}, 2 \mathrm{H}), 3.20-3.16(\mathrm{~m}$, $2 \mathrm{H}), 2.86-2.84(m, 2 \mathrm{H}), 2.41-2.37(m, 2 \mathrm{H}), 2.20$ $2.13(m, 4 \mathrm{H}), 2.01-1.96(m, 2 \mathrm{H}), 1.86-1.74(m, 2 \mathrm{H})$, and $1.55-1.52(m, 2 \mathrm{H})$.

PI-2 (HTABP-NDA). ${ }^{1} \mathrm{H}-\mathrm{NMR}$ (DMSO- $\left.d_{6}, \mathrm{ppm}\right)$ : $8.57(s, 1 \mathrm{H}), 7.71-7.69(d, 4 \mathrm{H}), 7.23-7.21(m, 4 \mathrm{H})$, 7.19-7.13 ( $m, 8 \mathrm{H}), 3.32-3.26(\mathrm{~m}, 2 \mathrm{H}), 3.20-3.16(\mathrm{~m}$, $2 \mathrm{H}), 2.86-2.83(m, 2 \mathrm{H}), 2.42-2.36(m, 2 \mathrm{H}), 2.20$ $2.12(m, 4 \mathrm{H}), 2.02-1.96(m, 2 \mathrm{H}), 1.85-1.74(m, 2 \mathrm{H})$, and $1.59-1.49(m, 2 \mathrm{H})$. 
PI-4 (HTABP-BisP). ${ }^{1} \mathrm{H}-\mathrm{NMR}$ (DMSO- $\left.d_{6}, \mathrm{ppm}\right)$ : 7.67-7.65 (d, 4H), 7.27-7.25 ( $m, 4 \mathrm{H}), 7.20-7.16(\mathrm{~m}$, $12 \mathrm{H}), 3.32-3.24(m, 2 \mathrm{H}), 3.17-3.13(m, 2 \mathrm{H}), 2.88$ $2.77(m, 2 \mathrm{H}), 2.44-2.37(m, 2 \mathrm{H}), 2.21-2.11(m, 2 \mathrm{H})$, $2.05-1.96(m, 4 \mathrm{H}), 1.85-1.73(m, 4 \mathrm{H})$, and 1.60 $1.55(m, 12 \mathrm{H})$.

PI-5 (HTABP-BisM). ${ }^{1}$ H-NMR (DMSO- $d_{6}$, ppm): 7.68-7.66 $(d, 4 \mathrm{H}), 7.32-7.30(m, 4 \mathrm{H}), 7.20-7.11(\mathrm{~m}$, $12 \mathrm{H}), 3.30-3.25(m, 2 \mathrm{H}), 3.18-3.16(m, 2 \mathrm{H}), 2.87-$ $2.83(m, 2 \mathrm{H}), 2.40-2.38(m, 2 \mathrm{H}), 2.17-2.10(m, 2 \mathrm{H})$, $2.02-1.98(m, 4 \mathrm{H}), 1.84-1.68(m, 4 \mathrm{H})$, and $1.61-$ $1.57(m, 12 \mathrm{H})$.

\subsubsection{Polyimides varnish and films preparation}

PI varnishes were prepared by dissolving the fully dried resins in a mixture solvent of NMP and BC (80:20, weight ratio) with a solid content of $6 \mathrm{wt} \%$. As an example, PI-3 varnish was made as follows. PI-3 resin (6 g) was added into a $250 \mathrm{ml}$ borosilicate glass flask equipped with an electromagnetic stirrer. Then, a mixed high-purity solvents containing NMP (75.2 g) and butyl cellulose (BC) (18.8 g) was added to afford a $6 \mathrm{wt} \%$ solution. The solution was stirred at room temperature overnight and then filtered through a $0.25 \mu \mathrm{m}$ Teflon syringe filter to remove any impurities. The obtained PI-3 varnish was used for the following film preparation.

PI-3 solution was spin-coated onto a clean indiumtin-oxide (ITO) glass. The thickness of the PI film was controlled by regulating the spinning rate. PI-3 film with the thicknesses in the range of several to dozens of micrometers for different evaluation was obtained by thermally baking the solution in a nitrogen flow according to the following heating procedure: $80^{\circ} \mathrm{C} / 2 \mathrm{~h}, 150^{\circ} \mathrm{C} / 1 \mathrm{~h}, 200^{\circ} \mathrm{C} / 1 \mathrm{~h}$ and $230^{\circ} \mathrm{C} / 1 \mathrm{~h}$.

The other PI varnishes and films were prepared according to a similar procedure as mentioned above.

\subsection{Fabrication of $L C$ cells}

The ITO glass substrates (size: $100 \mathrm{~mm} \times 100 \mathrm{~mm}$ $\times 0.5 \mathrm{~mm}$ ) were first cleaned with atmosphere pressure plasma treatment and then wiped with and acetone and dried. The PI varnish was spin coated on the ITO substrates according to a procedure of $1000 \mathrm{rpm} / 5 \mathrm{~s}$ and $5000 \mathrm{rpm} / 20 \mathrm{~s}$, followed by prebaked at $90{ }^{\circ} \mathrm{C}$ for $90 \mathrm{~s}$ on the hot plate. Uniform coatings with the thickness of $100 \pm 10 \mathrm{~nm}$ were obtained by regulating the spinning speed. Then, the PI-coated ITO substrates were main-cured for at $230^{\circ} \mathrm{C}$ for $20 \mathrm{~min}$ to complete the imidization. The
PI-coated ITO substrates were treatment with a semiautomatic rubbing machine (model: HY6018A, Qingdatianda Co., Ltd., Beijing, China) with a fixed rubbing strength of $67.2 \mathrm{~mm}$ in the current work. Then, the rubbing treated ITO substrates were placed on the dispersion glue machine (model: 300DS, Musashi Co., Ltd., Japan), and the epoxy sealant was coated under vacuum. The substrates were then preheated at $90^{\circ} \mathrm{C}$ for $90 \mathrm{~s}$ on the hot plate. Finally, two ITO substrates coated with the PI alignment layers with the opposite rubbing direction were assembled face to face into a sandwich structure and placed in the oven at $120^{\circ} \mathrm{C}$ for $10 \mathrm{~min}$ to solidify the sealant. The sandwich structure of the ITO substrates was cut into small cells $(10 \mathrm{~mm} \times 10 \mathrm{~mm} \times 0.5 \mathrm{~mm})$ with the cutting machine along the sealing frame. Then, the LC cells were filled into positive liquid crystals (MAT09-1284, Merck) with syringe and sealed with ultraviolet curable sealant. Finally, the LC cells were placed in an oven at $120^{\circ} \mathrm{C}$ for $1 \mathrm{~h}$ to finish the curing of the sealant. The obtained cells were used for following electro-optical property evaluation.

The properties of the LC cells, including pretilt angles $(T P A)$ of LC molecules, voltage holding ratio $(V H R)$, and residual directive circuit voltage $(R D C)$ were measured. $V H R$ and $R D C$ were measured with an optoelectronic system (model: 6254, TOYO Co., Ltd., Japan). For the VHR measurement, the applied voltage was $\pm 5 \mathrm{~V}$, pulse width was $60 \mu \mathrm{s}$, and frame period was $16.67 \mathrm{~ms}$. VHR measurements were performed 20 times and average values were obtained from these measurements. For the $R D C$ measurement, the DC stress was $5 \mathrm{~V}$, the discharge was $1 \mathrm{~s}$, and the measurement was $2400 \mathrm{~s}$. Pretilt angle (TPA) measurement of LC cells was performed by the crystal rotation method using the liquid crystal properties evaluation device (model: RETS-4600, Otsuka Electronics Co., Ltd., Japan).

\section{Results and discussion}

\subsection{Polyimide synthesis}

The high-purity HTABP dianhydride was polymerized with various aromatic diamines via a two-step chemical imidization procedure to afford the PI resins, as illustrated in Figure 1. The molecular design of the target PIs is mainly based on the solubility, thermal stability, the alignment ability for LC molecules, and the electro-optical properties of the LC cells. On one hand, the ester-linked semi-alicyclic HTABP moiety might provide good thermal 
and mechanical properties (rubbing resistance), low water absorption, and good optical transmittance for the derived PI alignment layers [38]. On the other hand, the diamines with different structural and functional features might provide the PI alignment layers various functionalities. MDA was used as a standard diamine for PI alignment layers development. NDA containing $-\mathrm{NH}-$ moiety with lone-pair electrons might provide PI alignment layers with faster discharging property. PPDA, BisP, and BisM containing flexible linkages in the molecular structures will enhance the solubility of the PI resins in organic solvents and might decrease the glass transition temperatures of the PI layers, which is beneficial for achieving a higher degree of imidization at the processing temperature of $230^{\circ} \mathrm{C}$ for TFT-LCD panel fabrications. All the polymerization mixtures were homogeneous, indicating good solubility of the PIs in the solvents. The intrinsic viscosities of the resulting PIs were in the range of 0.74 to $1.07 \mathrm{dl} \cdot \mathrm{g}^{-1}$ measured at $25^{\circ} \mathrm{C}$ in NMP (Table 1). White, continuous, and tough fibrous PI resins were obtained, which had numerical average molecular weights $\left(M_{\mathrm{n}}\right)$ of $11135 \sim 56329 \mathrm{~g} / \mathrm{mol}$ determined by GPC measurements (Table 1). The moderate to high $M_{\mathrm{n}}$ values in-
Table 1. Inherent viscosities and molecular weights of HTABP-PIs.

\begin{tabular}{|c|c|c|c|c|c|}
\hline PI & $\begin{array}{c}{[\boldsymbol{\eta}]_{\mathbf{i n h}^{\mathbf{a}}}} \\
{[\mathbf{d l} / \mathbf{g}]}\end{array}$ & $\begin{array}{c}\boldsymbol{M}_{\mathbf{n}}^{\mathbf{b}} \\
{[\mathbf{g} / \mathbf{m o l}]}\end{array}$ & $\begin{array}{c}\boldsymbol{M}_{\mathbf{w}}^{\mathbf{b}} \\
{[\mathbf{g} / \mathbf{m o l}]}\end{array}$ & PDI $^{\mathbf{b}}$ & $\mathbf{D I}^{\mathbf{c}}$ \\
\hline PI-1 & 0.81 & 13094 & 24331 & 1.86 & 85.2 \\
\hline PI-2 & 0.79 & 11135 & 15892 & 1.43 & 81.4 \\
\hline PI-3 & 1.07 & 56329 & 98350 & 1.75 & 87.9 \\
\hline PI-4 & 0.85 & 42626 & 74222 & 1.74 & 93.9 \\
\hline PI-5 & 0.74 & 26311 & 42796 & 1.63 & 100.0 \\
\hline
\end{tabular}

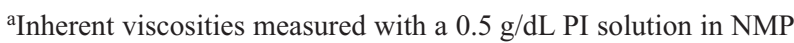
at $25^{\circ} \mathrm{C}$;

${ }^{\mathrm{b}} M_{\mathrm{n}}$ : number average molecular weight; $M_{\mathrm{w}}$ : weight average molecular weight; PDI: polydispersity index, PDI $=M_{\mathrm{w}} / M_{\mathrm{n}}$;

${ }^{\mathrm{c} D I}$ : degree of imidization.

dicated the good reactivity of HTABP dianhydride. In addition, the current HTABP-PIs showed the narrow polydispersity indices (PDI) in the range of 1.431.86 , indicating that few side reactions, such as branching or gelling occurred in the polymerization. The ATR-FTIR spectra of the HTABP-PI films along with the dianhydride monomer are shown Figure 2. The PI samples were curing at 230 and $300^{\circ} \mathrm{C}(\mathrm{em}-$ bedded in the spectra), respectively and the corresponding infrared absorptions were recorded. The former condition of $230^{\circ} \mathrm{C}$ is the standard curing condition for PI alignment layers in the current TFT-LCD
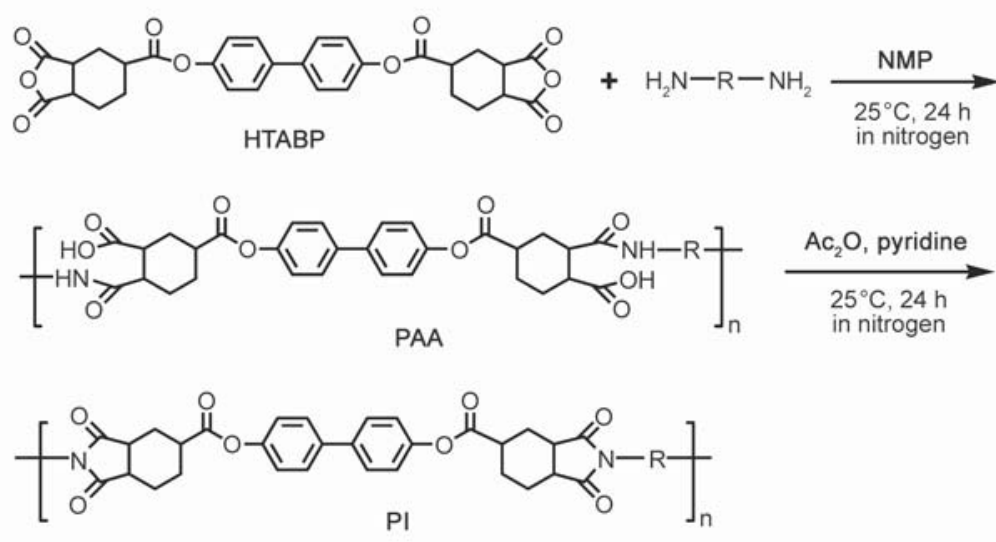

$\mathrm{H}_{2} \mathrm{~N}-\mathrm{R}-\mathrm{NH}_{2}$ :
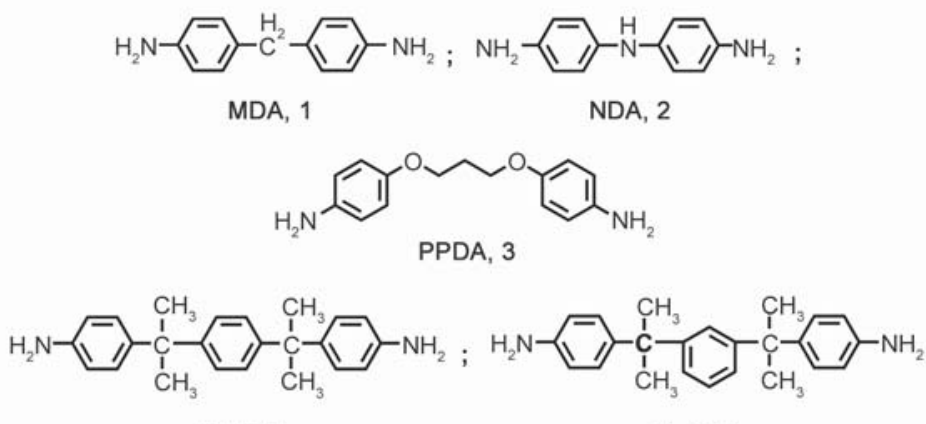

BisP, 4

BisM, 5

Figure 1. Synthesis of HTABP-PIs. 

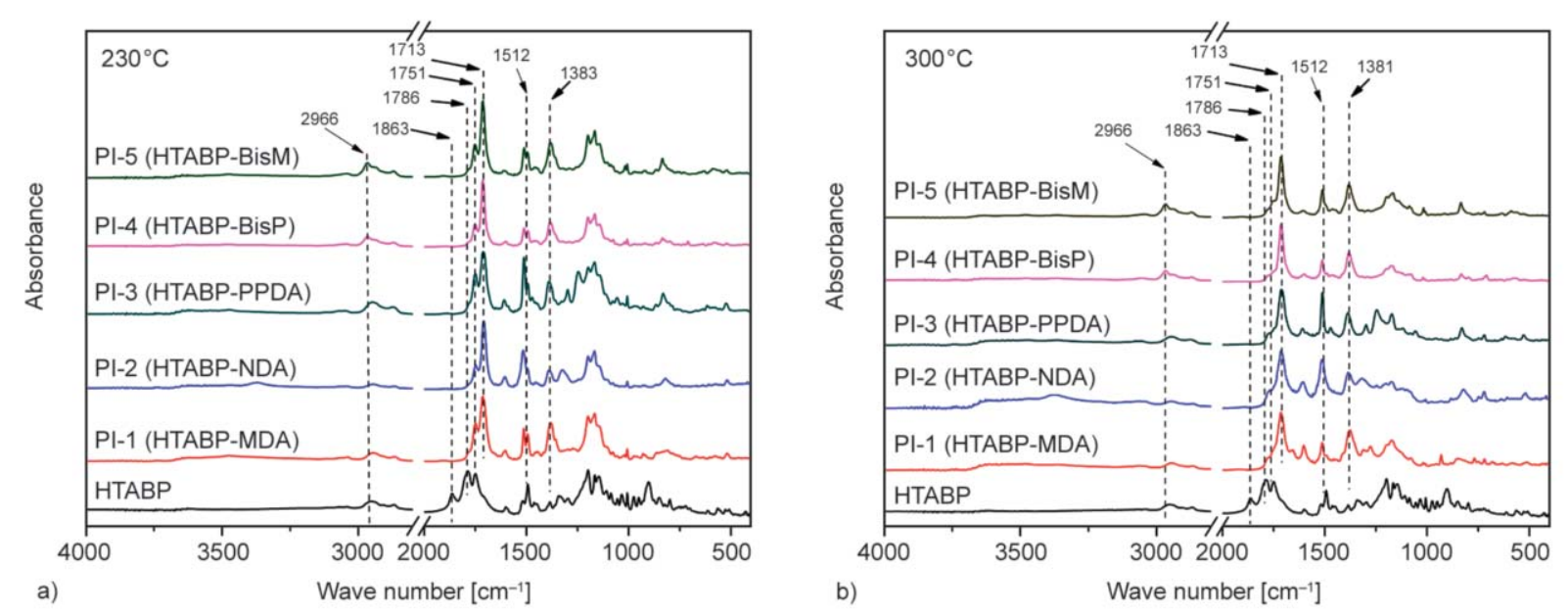

Figure 2. ATR-FTIR spectra of HTABP and derived PIs. (a) curing at $230^{\circ} \mathrm{C}$, (b) curing at $300^{\circ} \mathrm{C}$.

fabrication due to the limitation of some high-temperature sensitive components in the devices. The latter $300^{\circ} \mathrm{C}$ is considered to be the temperature at which full imidization could be achieved for the PI layers. Thus, the degree of imidization (DI) could be calculated according to the equation shown in 2.3 Section. According to the calculation, the HTABPPI layers exhibited DI values of $81.4-100 \%$ at the final curing temperature of $230^{\circ} \mathrm{C}$. The data imply that the chemical imidization procedure at room temperature could only achieve a partial imidization for the PIs. The degree of chemical imidization could be further increased by the aid of high temperature, such as $120^{\circ} \mathrm{C}$ for $3 \mathrm{~h}$ [28]. The parameter of DI is one of the important factors affecting the alignment properties of the PI alignment layers. Jung et al. [39] reported that the pretilt angles of LC molecules increased with the increasing DI values of the PI alignment layers. In addition, higher DI values usually afford PI alignment layers higher electrical resistivities, which is beneficial for achieving higher $V H R$ values for the derived LC cells. In the PIs, PI-2 exhibited a lowest DI of $81.4 \%$, while PI-5 showed the highest one of $100 \%$. This might be highly related to the molecular chain flexibility of the PIs. PI-5 possessed flexible 2-propyl segments and bulky metasubstituted benzene units in the structure, which are all prone to move at elevated temperatures. This might facilitate the evaporation of water byproducts during the imidization procedure at elevated temperatures; thus exhibiting higher DI value. Generally, the DI values higher than $80 \%$ can usually guarantee the practical applications of the PI alignment layers. Thus, the current HTABP-PIs with the high DI values might endow the LC cells with good $V H R$ features, which will be discussed below.

The chemical structures of the PIs can be confirmed by the FTIR spectra. The characteristic absorptions of anhydride carbonyls in HTABP, including the asymmetrical and symmetrical stretching vibrations of $>\mathrm{C}=\mathrm{O}$ at 1863 and $1751 \mathrm{~cm}^{-1}$, respectively disappeared in the spectra of all PIs. Alternatively, the characteristic absorptions of imide rings, including the asymmetrical and symmetrical stretching vibrations of imide $>\mathrm{C}=\mathrm{O}$ at 1786 and $1717 \mathrm{~cm}^{-1}$, respectively, and the absorptions of imide $\mathrm{C}-\mathrm{N}$ bonds at $1381 \mathrm{~cm}^{-1}$ were all clearly recorded. Meanwhile, the stretching vibration absorption peaks of saturated $\mathrm{C}-\mathrm{H}$ bonds in cyclohexane rings maintained in both of the spectra of HTABP and PIs. This spectral information implied the successful transition from the dianhydride monomer to the PI polymers.

The chemical structure of the HTABP-PI resins was further identified by the ${ }^{1} \mathrm{H}-\mathrm{NMR}$ measurements. The representative spectra of PI-3 and PI-5 along with the assignments of hydrogen protons are shown in Figure 3. The peaks at the chemical shift of 7.0 $8.0 \mathrm{ppm}$ in the spectra could be attributed to the absorptions of aromatic protons in the biphenylene units in HTABP moiety and the phenyl units in the diamine moiety. Comparatively, those absorptions at 1.5$4.5 \mathrm{ppm}$ ascribed to the aliphatic or alicyclic protons in cyclohexane ring or in methylene (PI-3) or methyl (PI-5) were also clearly observed for the PIs.

\subsection{Solubility}

The solubility of the HTABP-PI resins was quantitatively tested in various solvents at a solid content 

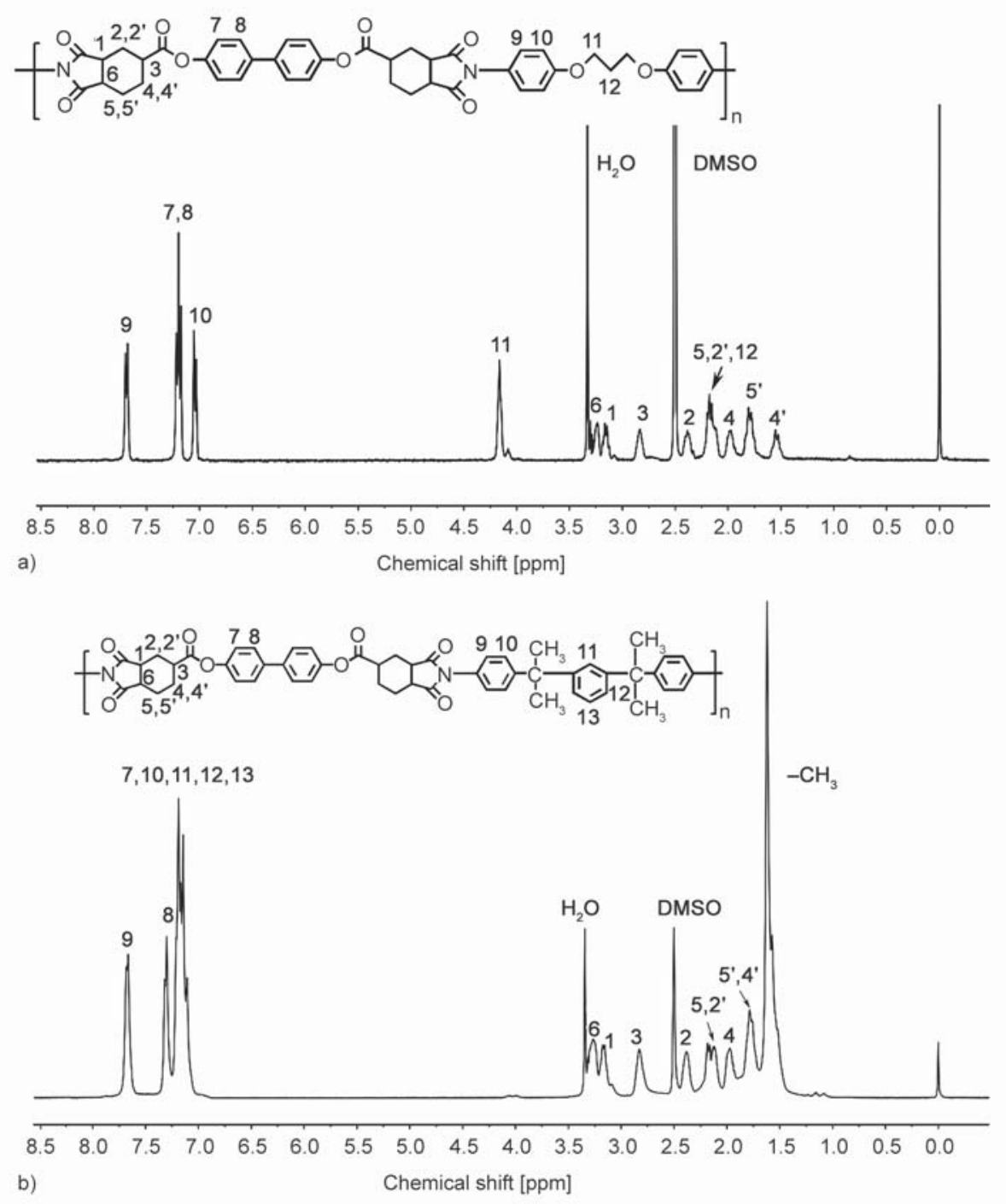

Figure 3. Typical ${ }^{1} \mathrm{H}-\mathrm{NMR}$ spectra of HTABP-PIs. (a) PI-3, (b) PI-5.

of $10 \mathrm{wt} \%$ and the results are tabulated in Table 2. As expected, the semi-alicyclic structure endowed the derived PI resins good solubility not only in polar aprotic solvents (NMP and DMAc), but in less polar GBL. All the PIs showed good resistance to BC and DPM. Since NMP and GBL are often used as the good solvents for PI alignment agents and $\mathrm{BC}$ and

Table 2. Solubility of HTABP-PI resins ${ }^{\mathrm{a}}$.

\begin{tabular}{|c|c|c|c|c|c|c|c|}
\hline \multirow{2}{*}{ PI } & \multicolumn{7}{|c|}{ Solvent $^{\mathbf{b}}$} \\
\cline { 2 - 8 } & NMP & DMAc & GBL & CHCl $_{3}$ & THF & BC & DPM \\
\hline PI-1 & ++ & ++ & ++ & + & + & - & - \\
\hline PI-2 & ++ & ++ & ++ & + & + & - & - \\
\hline PI-3 & ++ & ++ & ++ & ++ & + & - & - \\
\hline PI-4 & ++ & ++ & ++ & ++ & ++ & - & - \\
\hline PI-5 & ++ & ++ & ++ & ++ & ++ & - & - \\
\hline
\end{tabular}

a++: Soluble; +: partially soluble; -: insoluble.

${ }^{\mathrm{b}} \mathrm{GBL}$ : $\gamma$-butyrolactone; $\mathrm{CHCl}_{3}$ : chloroform; THF: tetrahydrofuran; BC: butyl cellosolve; DPM: dipropylene glycol monomethyl ether.
DPM as the leveling agents, the solubility behavior of the current HTABP-PIs makes them good candidates as components for alignment layer fabrication. The storage stability experiments of the PI alignment agents indicated that the viscosity of the PI varnishes (solid content: $6 \mathrm{wt} \%$; solvents: $\mathrm{NMP} / \mathrm{BC}=80: 20$, weight ratio; absolute viscosity: 50 60 $\mathrm{mPa} \cdot \mathrm{s}$ ) were stable during the storage at $25^{\circ} \mathrm{C}$ for more than half a year.

\subsection{Thermal properties}

The thermal properties of the HTABP-PIs were evaluated by the measurements of TGA and DSC and the results were shown in Figure 4 and Figure 5, and Table 3, respectively. Good thermal stability is critical for the practical applications of PI alignment layers in order to achieve stable alignment for LC molecules. It can be seen from Figure 4 and Table 3 that the PIs maintained good thermal stability up to $400^{\circ} \mathrm{C}$ 


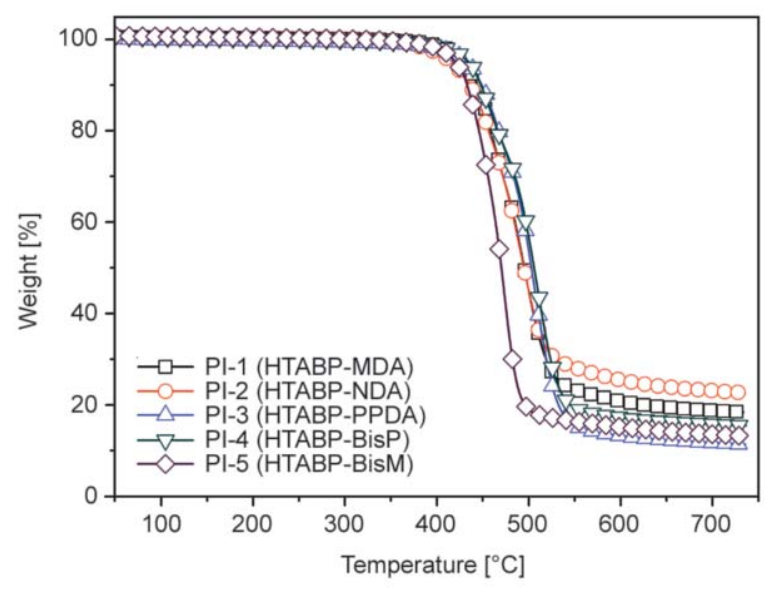

Figure 4. TGA plots of HTABP-PI films.

in nitrogen. The $5 \%$ weight loss temperature $\left(T_{5 \%}\right)$ of the PI alignment layers are in the range of 416$444^{\circ} \mathrm{C}$ and decreased according to the order of PI-1 > PI-4 > PI-3 > PI-5 > PI-2. PI-2 with the thermo-sensitive secondary amino $(-\mathrm{NH}-)$ in the structure showed the poorest thermal stability in the series. PI-5 with the meta-substituted structure showed the second lowest thermal stability. The PIs maintained $11.7-23.1 \%$ of their original weights at $700^{\circ} \mathrm{C}$.

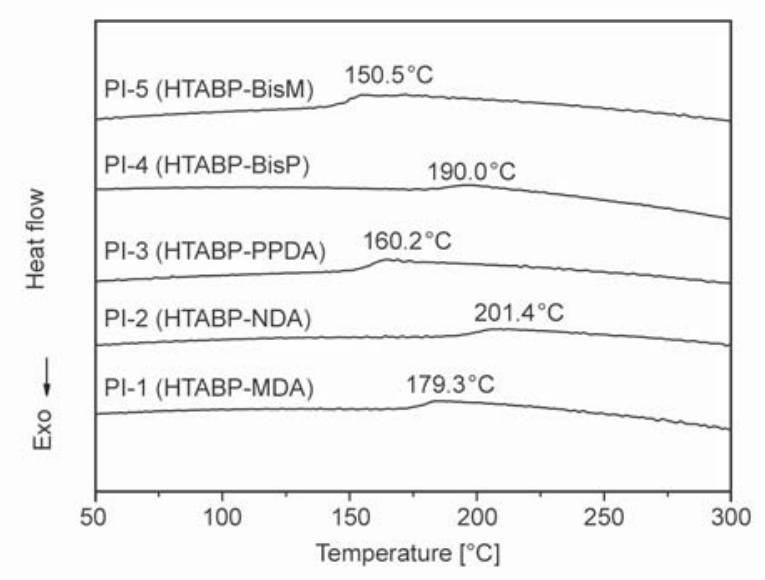

Figure 5. DSC plots of HTABP-PI films.
The glass transition temperatures $\left(T_{\mathrm{g}}\right)$ of the PI layers were determined by DSC measurement. It can be seen form Figure 5 that all the PIs exhibited clear glass transition behaviors during the heating. Basically, the semi-alicyclic HBPDA dianhydride endowed the PI alignment layers moderate $\mathrm{Tg}$ values in the range of $150.5-201.4{ }^{\circ} \mathrm{C}$ due to the flexible ester linkages and the non-conjugated cyclohexane unit in the structures. The $T_{\mathrm{g}}$ values of the PIs decreased with the order of PI-2 $>$ PI- $4>\mathrm{PI}-1>$ PI-3 $>$ PI-5. The meta-substituted molecular structure in PI-5 and the flexible aliphatic propane linkages in PI-3 made the molecular chains move easily at elevated temperatures, resulting in the lowest and second lowest $T_{\mathrm{g}}$ values for PI-5 and PI-3, respectively. Comparatively, PI-2 and PI-4 with relatively rigid molecular skeleton structures exhibited higher $T_{\mathrm{g}}$ values. Because the $T_{\mathrm{g}}$ values of the current HTABPPIs are all lower than the standard processing temperature of TFT-LCD panels $\left(230^{\circ} \mathrm{C}\right)$, the molecular chains of the polymers could move sufficiently during the curing process, which is advantageous to the removal of solvent and water by-products. Thus the PI alignment layers achieved a high degree of imidization (Table 1).

\subsection{Optical and electro-optical properties}

Optical and electro-optical properties, including optical transmittance, $V H R$, and $R D C$ features of the PI alignment layers are critical for their practical applications in TFT-LCD devices. On one hand, the PI alignment layers should possess good optical transmittance in the visible light region so as to achieve a high penetration of the backlight in the devices. On the other hand, they should provide the LC molecules stable alignment with suitable pretilt angles, high $V H R$ and low $R D C$ features.

Table 3. Thermal properties of HTABP-PI alignment layers and the electro-optical properties of LC cells.

\begin{tabular}{|c|c|c|c|c|c|c|c|c|}
\hline \multirow[b]{2}{*}{ PI } & \multicolumn{3}{|c|}{ Thermal properties $^{\text {a }}$} & \multicolumn{5}{|c|}{ Electro-optical properties ${ }^{\mathrm{b}}$} \\
\hline & $\begin{array}{c}\boldsymbol{T}_{\mathbf{g}} \\
{\left[{ }^{\circ} \mathbf{C}\right]}\end{array}$ & $\begin{array}{l}\boldsymbol{T}_{5 \%} \\
{\left[{ }^{\circ} \mathrm{C}\right]}\end{array}$ & $\begin{array}{c}R_{\mathrm{w} 700} \\
{[\%]}\end{array}$ & $\begin{array}{c}d \\
{[\mathrm{~nm}]}\end{array}$ & $\begin{array}{l}T_{400} \\
{[\%]}\end{array}$ & $\begin{array}{c}\text { TPA } \\
{\left[^{\circ}\right]}\end{array}$ & $\begin{array}{c}\text { VHR } \\
{[\%]}\end{array}$ & $\begin{array}{l}R D C \\
{[\mathrm{mV}]}\end{array}$ \\
\hline PI-1 & 179.3 & 444 & 18.8 & 102 & 99.1 & 2.21 & 98.04 & 1372 \\
\hline PI-2 & 201.4 & 416 & 23.1 & 105 & 92.2 & 2.23 & 97.43 & 915 \\
\hline PI-3 & 160.2 & 433 & 11.7 & 106 & 96.9 & 1.26 & 98.36 & 1170 \\
\hline PI-4 & 190.0 & 435 & 15.8 & 103 & 96.5 & 2.82 & 97.92 & 1920 \\
\hline PI-5 & 150.5 & 421 & 13.6 & 106 & 97.3 & 2.15 & 98.19 & 2146 \\
\hline
\end{tabular}

${ }^{\mathrm{a}} T_{\mathrm{g}}$ : glass-transition temperatures; $T_{5 \%}: 5 \%$ weight loss temperatures; $R_{\mathrm{w} 700}$ : residual weight ratio at $700{ }^{\circ} \mathrm{C}$;

${ }^{\mathrm{b}} d$ : thickness of PI alignment layer; $T_{400}$ : transmittance at the wavelength of $400 \mathrm{~nm}$; TPA: pretilt angles of LC molecules; VHR: voltage holding ratio; $R D C$ : residual direct current voltage. 


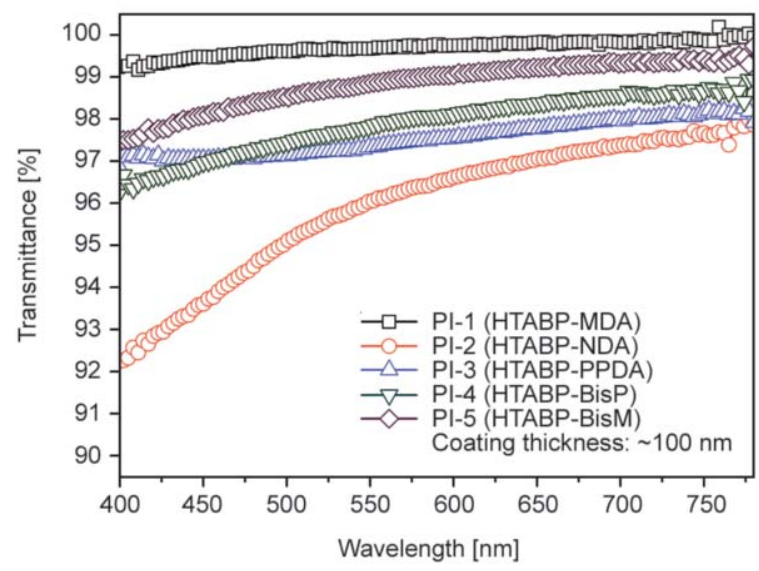

Figure 6. UV-Vis spectra of HTABP-PI layers.

Figure 6 shows the UV-Vis spectra of the PI thin layers at a thickness around $100 \mathrm{~nm}$. The thickness of the alignment layers and transmittances at the wavelength of $400 \mathrm{~nm}$ are summarized in Table 3. The PI layers showed good optical transparency with the transmittances higher than $92 \%$ at $400 \mathrm{~nm}$. The good optical transparency of the current PI layers is mainly attributed to the alicyclic cyclohexane rings in the dianhydride moiety. The intra- and inter-molecular charge transfer complexes (CTCs) between the electron-donating diamine moiety and the electron-accepting dianhydride unit are greatly reduced due to the non-conjugated cyclohexane structure in the dianhydride unit [7]. Thus, the absorption of the visible light by the PI molecules is obviously weakened. The transmittance values of the PI layers at $400 \mathrm{~nm}\left(T_{400}\right)$ decreased with the order of PI-1 $>$ PI-5 $>$ PI-3 $>$ PI-4 $>$ PI-2. PI-2 derived from NDA showed the lowest $T_{400}$ value, which is mainly due to the oxidative coloration of the diphenylamine unit in the structure at elevated temperatures.
LC cells were fabricated using the HTABP-PIs as the alignment layers according to the procedure shown in Figure 7. The alignment behavior to LC molecules, $V H R$ and $R D C$ features of the LC cells were investigated. The LC cell prototypes are based on the in-plane switching (IPS) and fringe field switching (FFS) modes of TFT-LCDs. The IPS and FFS modes of TFT-LCDs have been highly favored in portable displays in recent years due to the superior features, such as wide view angle, low operating voltage, low color shift, high transmittance and excellent pressure resistance for touch panels, and so on [40-42]. In IPS and FFS LCDs, in order to reduce the light leakage in a black state at diagonal viewing angles, planar alignment layer with lower TPA values are usually required [43].

It can be seen from Table 3 that the mechanical rubbing process with a cloth causes pretilt angles (TPA) in the range of $1.26-2.82^{\circ}$ for the HTABP-PIs. Homogenous alignment for LC molecules was achieved by the rubbing-induced anisotropy in the PI layers. PI-3 with the long alkyl chains (propane) in the main chain achieved a TPA value as low as $1.26^{\circ}$. Rigidrod LC molecules aligned along the zig-zag molecular chains in PI-3. Thus, PI-3 might be a promising alignment layers for the IPS or FFS modes of TFTLCDs.

Besides the TPA requirements for IPS and FFS LCDs, the highest possible $V H R$ and lowest possible $R D C$ features are also highly desired. As mentioned before, higher $V H R$ will result in the better contrast and low image flickering for TFT-LCDs. Figure 8 presents the VHR plots of the LC cells and the data are tabulated in Table 3. It can be seen from the plots that the HTABP-PI alignment layers endowed the

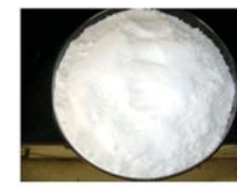

Monomer (HTABP)

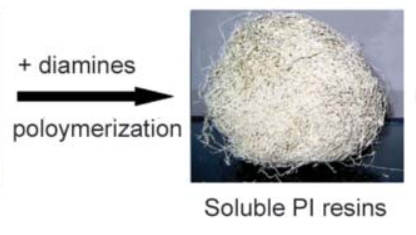

Soluble PI resins

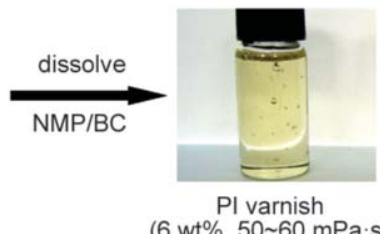

(6 wt\%, 50 60 mPa.s)

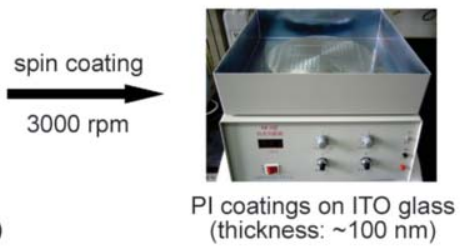

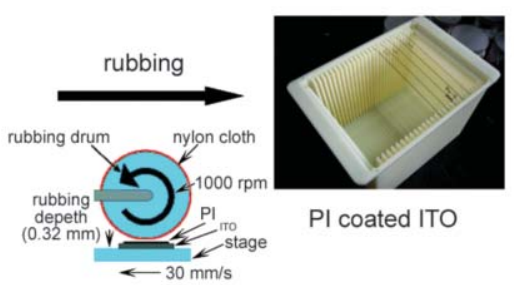

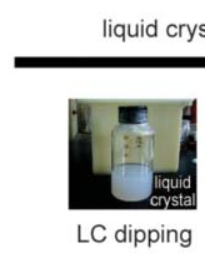

quid crystal cell fabrication
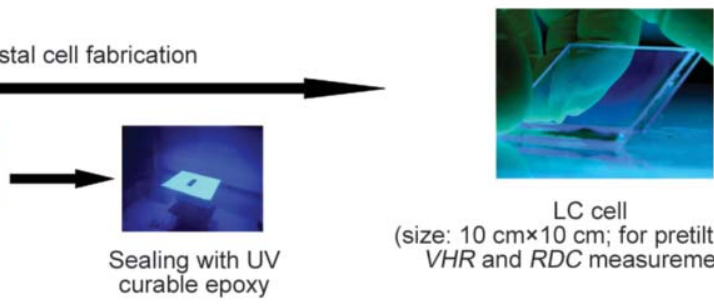

LC cell (size: $10 \mathrm{~cm} \times 10 \mathrm{~cm}$; for pretilt angle, VHR and RDC measurements)

Figure 7. Fabrication of LC cells using HTABP-PI as the alignment layers. 


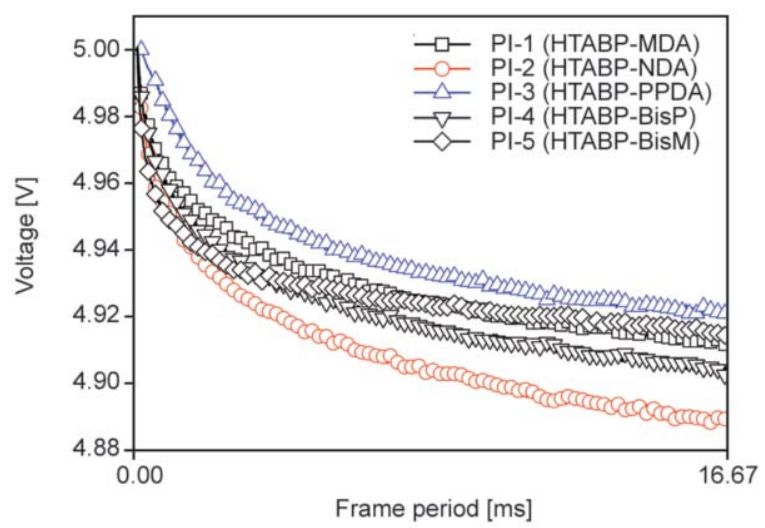

Figure 8. VHR plots of the LC cells with HTABP-PI as the alignment layers.

LC cells good VHR features with the values higher than $97 \%$ at room temperature. LC cells with the PI3 alignment layer showed the highest $V H R$ value of $98.36 \%$, whereas those with PI-2 showed the lowest one of $97.43 \%$, which is comparable to those of commercial PI alignment layers $(97.10 \%$ for SE7492K, Nissan Chemical, Japan) [44]. It has been revealed that the $V H R$ feature of LC cells is influenced by the charge transfer (CT) behaviors in the PI alignment layers [45]. The current results meant that the transfer of charge between PPDA and HTABP unit in PI-3 is more difficult than that between NDA and HTABP unit in PI-2. This might be due to the lone-pair electron in the-NH- bond in NDA, which provided a pathway for the charge transfer along the diphenylamine skeleton [46]. Thus, PI-2 showed the lowest $V H R$ feature.

Figure 9 shows the $R D C$ plots of the LC cells with HTABP-PI alignment layers. As mentioned before, adsorption and desorption of ions at the interface between LC and PI alignment layer play a crucial role

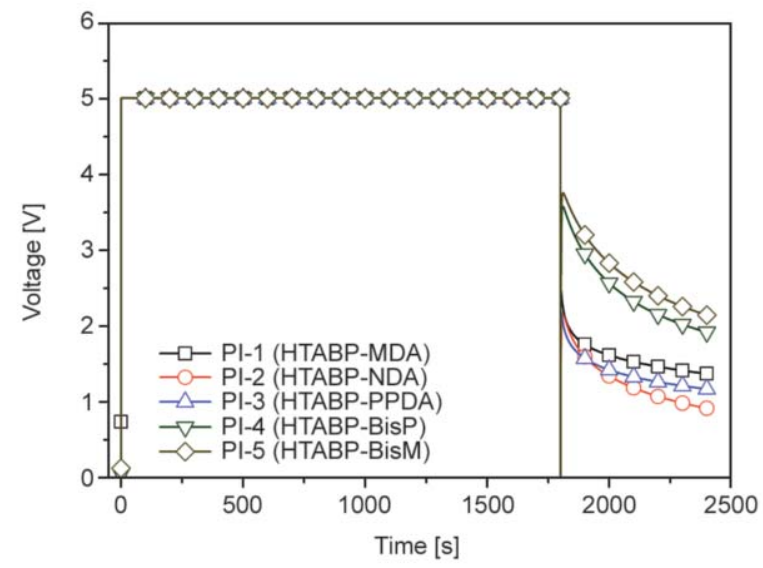

Figure 9. $R D C$ plots of the LC cells with HTABP-PI as the alignment layers. in $R D C$. Kim and coworkers revealed that the adsorption and desorption of ions was strongly influenced by the resistivity of the PI alignment layer. The one with lower resistivity in two orders showed much faster adsorption and desorption at the interface than that of the one with higher resistivity [22]. That is to say, the PI alignment layers with lower resistivity usually exhibited lower $R D C$ feature. Figure 10 shows the volume resistivity values of the HTABP-PI films. As expected, PI-2 with the lowest volume resistivity value exhibited the lowest $R D C$ feature. Basically, the effect of PI alignment layers on the $V H R$ and $R D C$ characteristics of LC cells is opposite. Low-resistivity PI-2 obtained low $R D C$ and low $V H R$ characteristics for the LC cells, while high-resistivity PIs provided the LC cells with high $V H R$ and high $R D C$ features. For example, PI-2 exhibited a $R D C$ value of $915 \mathrm{mV}$, which is comparable or lower than those of the commercial partially imidized PI alignment layers ( $4000 \mathrm{mV}$ for JALS-146, Japan Synthetic Rubber, Japan) [21]. Interestingly, PI-3 achieved both of the highest $V H R$ and relatively lower $R D C$ feature simultaneously. This can be interpreted as being due to the fact that the presence of the flexible and low-polar aliphatic chains in the diamine moiety in PI-3, on one hand, decreases the adsorption of harmful ions compared to the polar substituents (-NH-, phenyl, etc.) in PI-2, PI-4, and PI-5. On the other hand, the flexible and non-conjugated aliphatic chains and ether linkages in PI-3 endowed the polymer high volume resistivity. The synergic effects of the above factors afford PI-3 excellent combined optoelectronic properties. Nevertheless, hybrid of high$V H R$ imidized PI and low- $R D C$ PAA components is

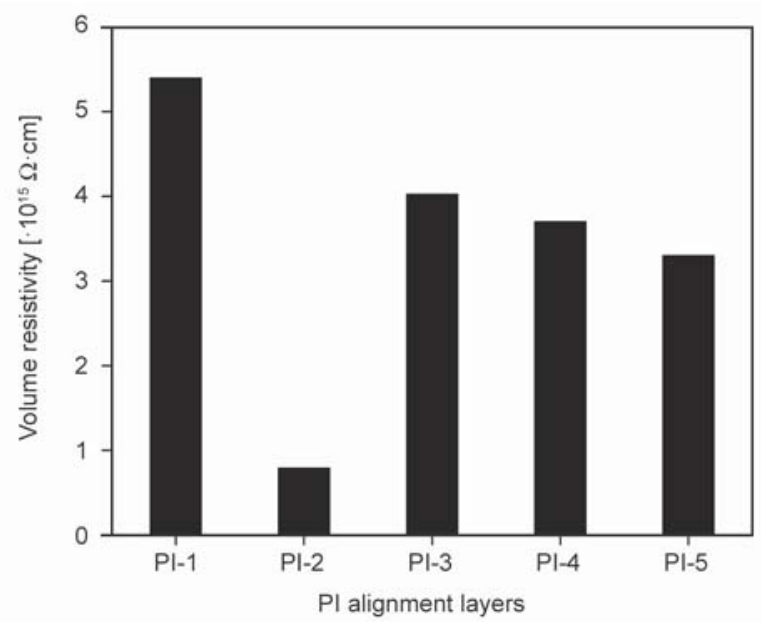

Figure 10. Volume resistivity of HTABP-PI films. 
still the most efficient way to develop high performance PI alignment layers for advanced TFT-LCDs.

\section{Conclusions}

Hybrid of PAA and imidized PI has been proven to be one of the most efficient ways for developing high performance PI alignment layers with excellent electro-optical properties. However, the very limited commercially available imidized PI species greatly restricted the development of PI alignment layers. In the current work, a series of PI alignment layers with different degree of imidization were successfully developed from a semi-alicyclic ester-containing dianhydride and various aromatic diamines. Experimental results indicated that the designed PI materials with specific structural characteristics, including high degree of imidization, low curing temperature, low molecular conjugation, high optical transparency and high volume resistivities, endowed the alignment layers good comprehensive properties for liquid crystal alignment. PI-3 derived from HTABP and aromatic diamine with linear ether-linked propane units $\left(-\mathrm{O}-\mathrm{CH}_{2} \mathrm{CH}_{2} \mathrm{CH}_{2}-\mathrm{O}-\right)$ in the main chain exhibited the best combined properties, including low pretilt angle $\left(T P A=1.26^{\circ}\right)$, high $\operatorname{VHR}(V H R=98.36 \%)$, relatively low $R D C(R D C=1170 \mathrm{mV})$, and good thermal stability $\left(T_{5 \%}=433^{\circ} \mathrm{C}\right)$. Good comprehensive properties make it good candidate as the alignment layers for the IPS or FFS modes of TFT-LCDs.

\section{Acknowledgements}

Financial support from the Fundamental Research Funds of China University of Geosciences, Beijing (No. 2652017345) is gratefully acknowledged.

\section{References}

[1] Liaw D-J., Wang K-L., Huang Y-C., Lee K-R., Lai J-Y., Ha S-K.: Advanced polyimide materials: Syntheses, physical properties and applications. Progress in Polymer Science, 37, 907-974 (2012).

https://doi.org/10.1016/j.progpolymsci.2012.02.005

[2] Albu R-M., Hulubei C., Stoica I., Barzic A-I.: Semi-alicyclic polyimides as potential membrane oxygenators: Rheological implications on film processing, morphology and blood compatibility. Express Polymer Letters, 13, 349-364 (2019). https://doi.org/10.3144/expresspolymlett.2019.29

[3] Liu X., Cao X-W., He G-J., Xing T-C.: Preparation and properties of a novel quaternary copolymerized thermoplastic polyimide. Express Polymer Letters, 13, 524 532 (2019).

https://doi.org/10.3144/expresspolymlett.2019.44
[4] Jun J., Lee J-H., Choi H-J., Moon S., Kim I-D., Lee H.: Fabrication of optically-functionalized colorless polyimide patterns with high durability. Applied Surface Science, 423, 881-886 (2017). https://doi.org/10.1016/j.apsusc.2017.06.277

[5] Li Z., Song H., He M., Liu J., Yang S.: Atomic oxygenresistant and transparent polyimide coatings from [3,5bis(3-aminophenoxy)phenyl]diphenylphosphine oxide and aromatic dianhydrides: Preparation and characterization. Progress in Organic Coatings, 75, 49-58 (2012). https://doi.org/10.1016/j.porgcoat.2012.03.007

[6] Tsai C-L., Yen H-J., Liou G-S.: Highly transparent polyimide hybrids for optoelectronic applications. Reactive and Functional Polymers, 108, 2-30 (2016). https://doi.org/10.1016/j.reactfunctpolym.2016.04.021

[7] Ni H-J., Liu J-G., Wang Z-H., Yang S-Y.: A review on colorless and optically transparent polyimide films: Chemistry, process and engineering applications. Journal of Industrial and Engineering Chemistry, 28, 16-27 (2015). https://doi.org/10.1016/j.jiec.2015.03.013

[8] Guo Y-Z., Shen D-X., Ni H-J., Liu J-G., Yang S-Y.: Organosoluble semi-alicyclic polyimides derived from 3,4-dicarboxy-1,2,3,4-tetrahydro-6-tert-butyl-1-naphthalene succinic dianhydride and aromatic diamines: Synthesis, characterization and thermal degradation investigation. Progress in Organic Coatings, 73, 768-777 (2013). https://doi.org/10.1016/j.porgcoat.2013.01.006

[9] Li F., Shen J-L., Liu X-F., Cao Z-H., Cai X., Li J-L., Ding K., Liu J-K., Tu G-L.: Flexible QLED and OPV based on transparent polyimide substrate with rigid alicyclic asymmetric isomer. Organic Electronics, 51, 54 61 (2017).

https://doi.org/10.1016/j.orgel.2017.09.010

[10] Hu X., Mu H., Wang Y., Wang Z., Yan J.: Colorless polyimides derived from isomeric dicyclohexyl-tetracarboxylic dianhydrides for optoelectronic applications. Polymer, 134, 8-19 (2018). https://doi.org/10.1016/j.polymer.2017.11.042

[11] Hasegawa M., Watanabe Y., Tsukuda S., Ishii J.: Solution-processable colorless polyimides with ultralow coefficients of thermal expansion for optoelectronic applications. Polymer International, 65, 1063-1073 (2016). https://doi.org/10.1002/pi.5152

[12] Kang H., Park J-S., Sohn E-H., Kang D., Rosenblatt C., Lee J-C.: Polyimide blend alignment layers for control of liquid crystal pretilt angle through baking. Polymer, 50, 5220-5227 (2009). https://doi.org/10.1016/j.polymer.2009.09.023

[13] Nishikawa M.: Design of polyimides for liquid crystal alignment films. Polymer for Advanced Technology, 11, 404-412 (2000).

https://doi.org/10.1002/10991581(200008/12)11:8/12<404::AID-PAT41>3.0.CO;2-T 
[14] Wang F., Shao L., Bai Q., Che X., Liu B., Wang Y.: Photo-induced vertical alignment of liquid crystals via in situ polymerization initiated by polyimide containing benzophenone. Polymers, 9, 233/1-233/10 (2017). https://doi.org/10.3390/polym9060233

[15] Nishikawa M.: Development of novel polyimide alignment films for liquid crystal display televisions. Journal of Photopolymer Science and Technology, 24, 317-320 (2011). https://doi.org/10.2494/photopolymer.24.317

[16] Chen P-S., Huang C-C., Liu Y-W., Chao C-Y.: Effect of insulating-nanoparticles addition on ion current and voltage-holding ratio in nematic liquid crystal cells. Applied Physics Letters, 90, 211111/1-211111/3 (2007). https://doi.org/10.1063/1.2740581

[17] Gauza S., Li J., Wu S-T., Spadło A., Dabrowski R., Tzeng Y-N., Cheng K-L.: High birefringence and high resistivity isothiocyanate-based nematic liquid crystal mixtures. Liquid Crystals, 32, 1077-1085 (2005). https://doi.org/10.1080/02678290500303007

[18] Mizusaki M., Enomoto S., Hara Y.: Generation mechanism of residual direct current voltage for liquid crystal cells with polymer layers produced from monomers. Liquid Crystals, 44, 609-617 (2017). https://doi.org/10.1080/02678292.2016.1225839

[19] Jeon Y-J., Hwang J-Y., Seo D-S., Kim H-Y.: Voltage holding ratio and residual DC property of the IPS-LCD on rubbed polymer layers by voltage-transmittance hysteresis method. Molecular Crystals and Liquid Crystals, 410, 369-380 (2004).

https://doi.org/10.1080/15421400490433325

[20] Choi N., Jung J., Cheong B., Yoon H., Hong M.: Reduction of residual DC voltage via RC matching in LCD. Materials Research Express, 5, 126305/1-126305/8 (2018).

https://doi.org/10.1088/2053-1591/aae1b7

[21] Lee T. R., Kim J. H., Lee S. H., Jun M. C., Baik H. K.: Investigation on newly designed low resistivity polyimide-type alignment layer for reducing DC image sticking of in-plane switching liquid crystal display. Liquid Crystals, 44, 738-747 (2017).

https://doi.org/10.1080/02678292.2016.1239775

[22] Kim D. H., Kim J. H., Kwon Y. R., Ahn S. H., Srivastava A. K., Lee S. H.: Investigation on ion movement in the fringe-field switching mode depending on resistivity of alignment layer and dielectric anisotropic sign of liquid crystal. Liquid Crystals, 42, 486-491 (2015). https://doi.org/10.1080/02678292.2014.1000407

[23] Kim T. Y., Kim W. J., Lee T. H., Kim J. E., Suh K. S.: Electrical conduction of polyimide films prepared from polyamic acid (PAA) and pre-imidized polyimide (PI) solution. Express Polymer Letters, 1, 427-432 (2007). https://doi.org/10.3144/expresspolymlett.2007.60

[24] Ahn H. J., Kwak C-H., Park H., Lee J-H., Jun M-C., Kang I-B.: Phase separation of photo-aligned polyimide blends for robust reliability. SID International Symposium Digest of Technical Papers, 48, 582-584 (2017). https://doi.org/10.1002/sdtp.11700
[25] Sato T., Sawahata K., Endo H., Fukuro H.: Influence of polyamide structures on electrical properties of activematrix liquid-crystal cells. SID International Symposium Digest of Technical Papers, 29, 738-741 (1998). https://doi.org/10.1889/1.1833866

[26] Lee S-W., Park S-Y., Shin D-M.: Synthesis and photoalignment properties of novel polyimides with cyclobutane-1,2,3,4-tetracarboxylic dianhydride (CBDA). Molecular Crystals and Liquid Crystals, 620, 159-165 (2015). https://doi.org/10.1080/15421406.2015.1095440

[27] Yang B-N., Shin D-M.: Photo-alignment using benzophenone sensitized photodecomposition of the polyimide. Molecular Crystals and Liquid Crystals, 599, 118-124 (2014). https://doi.org/10.1080/15421406.2014.935973

[28] Nishikawa M., Yokoyama Y., Bessho N., Seo D-S., Iimura Y., Kobayashi S.: Synthesis of a novel organicsolvent-soluble polyimide and its application to alignment film for liquid crystal displays. Japanese Journal of Applied Physics, 33, L810-L812 (1994). https://doi.org/10.1143/JJAP.33.L810

[29] Nishikawa M., Suganuma T., Tsuda Y., Bessho N., Iimura Y., Kobayashi S.: Properties of voltage holding ratios of liquid crystal cells using organic-solvent-soluble polyimide alignment films. Japanese Journal of Applied Physics, 33, L1113-L1116 (1994). https://doi.org/10.1143/JJAP.33.L1113

[30] Nishikawa M., Sano K., Miyamoto T., Yokoyama Y., Bessho N., Seo D-S., Iimura Y., Kobayashi S.: Pretilt angles of liquid crystal on organic-solvent-soluble polyimide alignment films. Japanese Journal of Applied Physics, 33, 4152-4153 (1994). https://doi.org/10.1143/JJAP.33.4152

[31] Wu X., Liu J., Jiang G., Zhang Y., Guo C., Zhang Y., Zhang X.: Highly transparent preimidized semi-alicyclic polyimide varnishes with low curing temperatures and desirable processing viscosities at high solid contents: Preparation and applications for LED chip passivation. Journal of Materials Science: Materials in Electronics, 30, 549-560 (2019). https://doi.org/10.1007/s10854-018-0321-5

[32] Zhang Y., Liu J., Wu X., Bi H., Jiang G., Zhi X., Qi L., Zhang X.: Synthesis and characterization of thianthrenecontaining preimidized soluble polyimide resins and the derived films with high refractive indices and good optical transparency. Journal of Polymer Research, 26, 2/1-2/11 (2019). https://doi.org/10.1007/s10965-018-1664-6

[33] Guo C-Y., Wu X., Liu J-G., Zhang Y., Zhang X-M.: Preparation and properties of high-whiteness polyimide ultrafine fabrics by electrospinning from organo-soluble semi-alicyclic polyimide resins. Journal of Photopolymer Science and Technology, 31, 27-36 (2018). https://doi.org/10.2494/photopolymer.31.27 
[34] Liu J-G., Guo Y-Z., Yang H-X., Yang S-Y.: Organo-soluble semi-alicyclic polyimides derived from substituted-tetralin dianhydrides and aromatic diamines: Synthesis, characterization and potential applications as alignment layer for TFT-LCDs. in 'Optoelectronics - Advanced materials and devices' (eds.: Pyshkin S., Ballato J.) Intech, Rijeka, 269-290 (2013).

https://doi.org/10.5772/51182

[35] Kulszewicz-Bajer I., Różalska I., Kuryłek M.: Synthesis and spectroscopic properties of aniline tetramers. Comparative studies. New Journal of Chemistry, 28 , 669-675 (2004).

https://doi.org/10.1039/B311096F

[36] Faghihi K.: New optically active poly(amide-imide)s based on $N, N^{\prime}$-(pyromellitoyl)-bis-L-amino acid and 1,3-bis(4-aminophenoxy) propane: Synthesis and characterization. Journal of Applied Polymer Science, 109, 74-81 (2008).

https://doi.org/10.1002/app.27675

[37] Lee S-C., Tai F-C., Wei C-H., Yu J-I.: ATR-FTIR and nanoindentation measurements of PMDA-ODA polyimide film under different curing temperature. Materials Transactions, 48, 1554-1557 (2007). https://doi.org/10.2320/matertrans.MER2007045

[38] Zhou Y., Chen G., Wang W., Wei L., Zhang Q., Song L., Fang X.: Synthesis and characterization of transparent polyimides derived from ester-containing dianhydrides with different electron affinities. RSC Advances, 5, 79207-79215 (2015).

https://doi.org/10.1039/C5RA16574A

[39] Jung J. T., Yi M. H., Kwon S. K., Chol K. Y.: Aromatic polyimides containing pendant alkyl groups for liquid crystal alignment layers. Molecular Crystals and Liquid Crystals, 333, 1-13 (1999). https://oi.org/10.1080/10587259908025991
[40] Choi T-H., Oh S-W., Park Y-J., Choi Y-Y., Yoon T-H.: Fast fringe-field switching of a liquid crystal cell by two-dimensional confinement with virtual walls. Scientific Reports, 6, 27936/1-27936/9 (2016). https://doi.org/10.1038/srep27936

[41] Tahata S., Yuuki A.: Optimization of the pretilt angle of liquid crystal alignment for IPS Mode LCD. Molecular Crystals and Liquid Crystals, 419, 13-26 (2004). https://doi.org/10.1080/15421400490465780

[42] Kim D. H., Lim Y. J., Kim D. E., Ren H. W., Ahn S. H., Lee S. H.: Past, present, and future of fringe-field switching-liquid crystal display. Journal of Information Display, 15, 99-106 (2014).

https://doi.org/10.1080/15980316.2014.914982

[43] Lee T. R., Kim J. H., Lee S. H., Jun M. C., Baik H. K.: Suppressing pretilt angle for enhancing black quality in diagonal viewing angle of homogenously aligned liquid crystal display. Liquid Crystals, 44, 1146-1156 (2017). https://doi.org/10.1080/02678292.2016.1269370

[44] Kang H., Lee J-C., Nam B-U., Bae J. W.: Liquid crystal alignment behavior on transparent cellulose films. RSC Advances, 5, 38654-38659 (2015). https://doi.org/10.1039/C5RA03713A

[45] Hasegawa M., Horie K.: Photophysics, photochemistry, and optical properties of polyimides. Progress in Polymer Science, 26, 259-335 (2001). https://doi.org/10.1016/S0079-6700(00)00042-3

[46] Ganesan S., Muthuraaman B., Mathew V., Madhavan J., Maruthamuthu P., Suthanthiraraj S. A.: Performance of a new polymer electrolyte incorporated with diphenylamine in nanocrystalline dye-sensitized solar cell. Solar Energy Materials and Solar Cells, 92, 1718-1722 (2008).

https://doi.org/10.1016/j.solmat.2008.08.004 